\title{
Lunar Periodicity of Reproduction in the Planktonic Foraminifer Hastigerina pelagica
}

\author{
M. Spindler ${ }^{1}$, C. Hemleben ${ }^{1}$, U. Bayer ${ }^{1}$, A. W. H. Bé ${ }^{2}$ and O. R. Anderson ${ }^{2}$ \\ ${ }^{1}$ Institut und Museum für Geologie und Paläontologie, Sigwartstraße 10, D-7400 Tübingen, Federal Republic of Germany \\ ${ }^{2}$ Lamont-Doherty Geological Observatory, Palisades, New York 10964, USA
}

\begin{abstract}
Lunar periodicity in the reproductive cycle of a protozoan is reported for the first time. Hastigerina pelagica (d'Orbigny) releases gametes in a rhythmic cycle. Gametogenesis generally takes place 3 to 7 days after full moon, exhibiting a synodic moon cycle. Field observations suggest that in the open ocean almost all individuals may undergo gametogenesis at the same time. Reproduction in the laboratory is synchronous with that in the natural environment. Cultures were maintained in a controlled-climate room with a $12 \mathrm{~h}$ light/ $12 \mathrm{~h}$ dark cycle at habitat temperatures. Laboratory conditions, however, may disrupt the timing of the reproductive cycle since the number of individuals actually releasing gametes in the laboratory depends on the collecting date. The closer to the time of reproduction the protozoans are collected, the more individuals will release gametes. Individuals collected 13 or more days before full moon, very seldom reproduce.
\end{abstract}

\section{INTRODUCTION}

Orientation in time and biological rhythms of marine animals have been reviewed in Volume II of Marine Ecology' by Enright (1975). In several marine invertebrates and vertebrates (e.g. polychaetes, crustaceans, fishes) reproduction is triggered by rhythmical maturation. Some rhythmical patterns in reproductive activities are quite closely related to the synodic moon cycle of 29.5 days. In the laboratory, most of these organisms exhibit such a rhythm, indicating the presence of a timing mechanism or 'biological clock' within the organism (DeCoursey, 1976; Saunders, 1977). In this paper we document reproductive lunar periodicity in the planktonic foraminifer Hastigerina pelagica.

\section{MATERIAL AND METHODS}

Hastigerina pelagica were either collected by plankton net tows or individually by SCUBA diving 4 to 6 miles south of Bermuda and 2 to 4 miles west of Barbados. For further details of the collection methods see Bé et al. (1977). The cultures were maintained in a controlled-climate room with a $12 \mathrm{~h}$ light/12 h dark cycle at close to in-situ temperatures. The test material was kept in crystallizing dishes $(475 \mathrm{ml})$ in natural seawater and fed twice a week with 2- or 3-day old Artemia salina nauplii.

\section{RESULTS}

Since 1975 we have kept several thousand individuals of 13 different species of planktonic foraminiferans in culture at the Biological Stations of Bermuda and Barbados. Among these species, Hastigerina pelagica exhibits a reproductive cycle that is influenced by environmental factors. This conclusion was reached when we observed that individuals kept in different culture dishes undergo gametogenesis simultaneously on a particular day. For example, on May 8, 1977, 94 out of 118 individuals released gametes during the

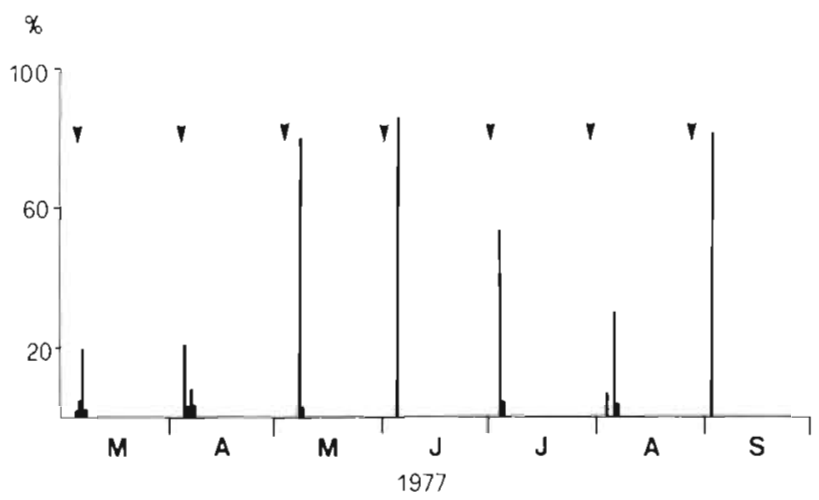

Fig. 1. Hastigerina pelagica. Data on mass gametogenesis for the period March to September 1977. X-axis: time scale; $Y$ axis: percentages of collected animals which released gametes on the days indicated. Days of full moon are indicated by arrow heads 
same afternoon. One additional individual followed the next day. Thus $81 \%$ of the observed $H$. pelagica reproduced within 2 days.

After similar observations obtained at monthly intervals and after comparing the reproductive data of Hastigerina pelagica with the lunar cycle, it became apparent that mass gametogenesis generally occurred 3 to 7 days after full moon. Figure 1 shows data from 7 consecutive months in 1977. This is a representative sample of our total observations from June 1975 to June 1978. In 717 cases of gamete release observed in $H$. pelagica, $85.4 \%$ of the individuals released gametes within 5 days between the 3 rd and 7 th day after full moon (Fig. 2).

Some individuals released their gametes a few days before or after this time. However, $98.3 \%$ of all observed cases of gametogenesis occurred in the time span

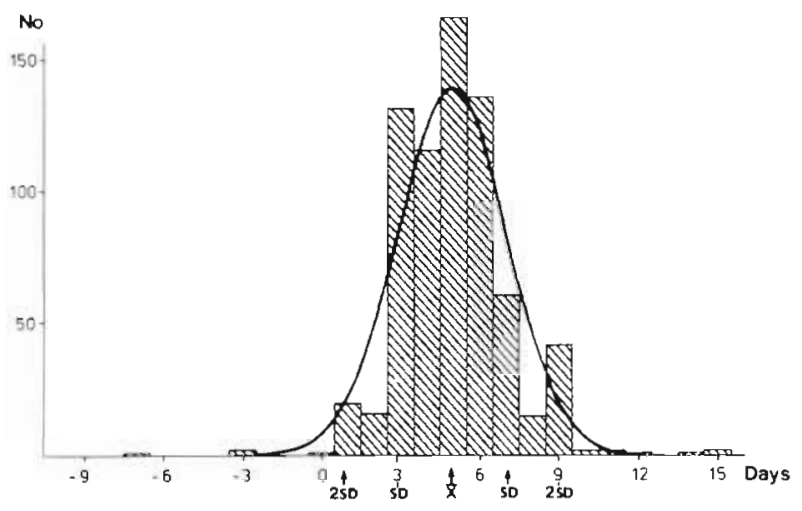

Fig. 2. Hastigerina pelagica. Absolute numbers of 32 samples collected at different times containing individuals which had undergone gametogenesis in relation to the day of full moon $=0$ days. $-9=9$ days before full moon; $15=15$ days after full moon; $\overrightarrow{\mathrm{x}}=$ mean; $\mathrm{SD}=1$ standard deviation; $2 \mathrm{SD}=2$ standard deviations

between 1 and 9 days after full moon, which covers the range of 2 standard deviations of the gaussian distribution. The remaining $1.7 \%$ did not undergo gametogenesis during this time and represented only 12 individuals (Fig. 2).

Observations on gametogenesis were not made from December through February 1976/77 and 1977/78 because Hastigerina pelagica is rarely found around Bermuda during winter (Bé, 1960; Bé et al., 1971). The numbers of individuals during this period were too small to document cyclicity. Therefore, observations were continued during the winter months in Barbados, where $H$. pelagica was more abundant. Part of these individuals released gametes at the predicted time after every full moon. Since gametogenesis occurs simultaneously both in the laboratory and in the open ocean, we can predict reproductive timing.

A few (3-5) days after gametogenesis occurred in the laboratory, very few Hastigerina pelagica were observed in the open ocean, although a week before we had been able to collect hundreds of them. Furthermore, SCUBA-collected individuals, taken 1-3 days after full moon exhibit typical signs of impending gametogenesis; i. e. red coloration of the cytoplasm and incipient disintegration of the bubble capsule (Spindler et al., 1978). After this, H. pelagica disappears from the surface water, indicating that almost all adults undergo gametogenesis. Since the disappearance of $H$. pelagica from surface water has been repeatedly observed immediately after gametogenesis, it seems unlikely that distributional patchiness is involved. Since samples were always collected at the same time of day, it is equally unlikely that diurnal vertical migration is involved.

The assumption that almost all individuals will undergo gametogenesis at the same time seems to contradict the fact that in culture only $48 \%$ (717 out of 1506) of all individuals released gametes. On the other hand, the day of collection influences the ability of Hastigerina pelagica to reproduce in laboratory culture. Individuals collected 13 or more days before full moon very seldomly reproduced. In contrast, $6 \%$ reproduced of the individuals sampled $7-8$ days before full moon, while about $50 \%$ exhibited predictable gametogenesis when collected 1-2 days before full moon. The solid-line histogram in Fig. 3 demonstrates the relationship between collection date and percentage of gamete-producing individuals. There is an almost linear increase up to 3 days after full moon. From the 4 th day on, the numbers decrease rapidly. A linear regression analysis of all data up to 3 days after full

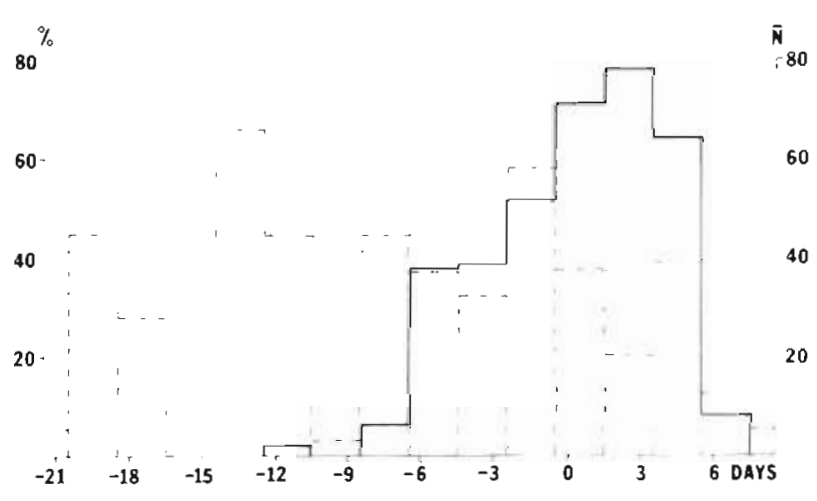

Fig. 3. Hastigerina pelagica. Relationship between collection day and percentage of individuals releasing gametes. Solid line: percentages of individuals which released gametes at their normal reproduction time (3-7 days after full moon); also given is the actual day of their collection. Broken line: average numbers of individuals collected at certain times in relation to full moon $=0$ days. $-21=21$ days before full moon: $6=6$ days after full moon. Although sufficient individuals were collected during the period 21 to 13 days before full moon none of these reproduced 
moon yields a correlation coefficient of more than 0.8 (significance exceeding $99 \%$ ).

The pronounced decrease in number following the 3rd day after full moon can be explained by the fact that reproduction occurs 3-7 days after full moon. During reproduction the protozoans descend to deeper water and thus beyond our collection-depth range. Therefore the percentage of individuals which do not undergo gametogenesis increases in the surface-water samples.

From the data shown in Figure 3 we deduce the following hypothetical rule: The closer the collection time to the date of full moon, the greater is the number of individuals that will release gametes. Consequently, we explain the pattern in Figure 3 by external coincidences superimposed on the internal clock, i. e. the number of individuals undergoing gametogenesis in the laboratory depends on the degree of gametogenetic induction by this trigger previous to collecting. The mean inductive effect increases with full moon. Other triggers are known to cause mass reproduction in marine animals: temperature, salinity, food or chemical substances (pheromones) which are released during reproduction (For details consult 'Marine Ecology', Volume I: Kinne, 1970, 1971, 1972). It is unlikely that these factors are involved in gametogenesis in Hastigerina pelagica because we maintained the individuals in natural seawater from the collecting site and adjusted the temperature to field conditions (Bé et al., 1977). A sudden change in one of these parameters could not occur in culture and hence cannot be responsible for the precise synchroneity between gamete release in the laboratory and the natural environment.

The fact that individuals collected long enough before the actual reproduction date fail to release gametes, although they were kept in exactly the same water as individuals caught some days later, shows that water quality has no influence on the timing of the reproductive processes. Placing individuals collected 3 weeks before the gametogenesis date into water in which other individuals have just released gametes does not stimulate reproduction; hence it is unlikely that pheromones enhance gamete release.

In Hastigerina pelagica, a diurnal rhythm is superimposed on the lunar reproductive cycle. Gamete release always occurs during the afternoon, mainly between 3 p. m. and 6 p. m. (Spindler et al., 1978). This precise timing of simultaneous gamete release enhances the probability of gamete fusion in the open ocean and would be particularly beneficial if $H$. pelagica belonged to the more advanced protozoan species with heterogamic reproduction. From calculations of the number of gametes released by a single $H$. pelagica (Spindler et al., 1978) and the population density of this species in surface waters shortly before reproduction we expect about 500000 gametes $\mathrm{m}^{-3}$.

Based on the reproductive periodicity and combining data from laboratory and field observations, we believe that the generation time of Hastigerina pelagica is 29 days. There is a possibility that the generation time may be a multiple of 29 days because a few of the individuals kept in the laboratory failed to reproduce during the full moon period following collection but did so 29 days later. Individuals that do not reproduce survive as long as 118 days in laboratory culture (Bé et al., 1977). H. pelagica's generation time is roughly twice as long as that of other planktonic foraminiferans of about 2 weeks calculated by Berger (1969, 1970, 1971) and Berger and Soutar (1970).

\section{DISCUSSION}

The synchronization of gamete release in metazoan invertebrates due to lunar periodicity is a well known mechanism to provide optimum opportunity for contact between gametes of different parents. We suspect that lunar periodicity in gamete release by Hastigerina pelagica may serve a similar function thus increasing the generality of reproductive lunar cycles to include protozoans as well as metazoan invertebrates. Moreover, the synchronization of gamete release from many mother cells simultaneously may indicate that $H$. pelagica is heterogamous and therefore is phylogenetically more advanced than other planktonic foraminiferans which apparently do not exhibit a lunar reproductive periodicity (Bé and Anderson, 1976; Bé et al., 1977). Moreover, $H$. pelagica is a unique species of planktonic foraminiferans which has evolved several morphological structures (e.g. triradial spines, cytoplasmic bubble capsule, chamber walls containing an abundant organic matrix) not found in other planktonic Foraminifera and thus may further indicate its more advanced phylogenetic stage of development. Although reproduction occurs according to the lunar cycle we do not know what triggers gamete release. It appears unlikely that the amount of light during the nights is responsible for the timing of gamete release. We never observed any differences in the ability, or number of individuals reproducing, related to skies being overcast or clear prior to full moon. In addition, very few individuals, collected several days before a full moon, failed to reproduce 3-7 days after that full moon but did so exactly one month later. These individuals were kept for more than 30 days in the laboratory without being exposed to any light during the nights.

These observations raise interesting questions about the mechanism of the physiological clock in Hastigerina pelagica and, possibly, the sensory perceptive 
processes whereby these single-cell organisms coordinate their reproductive cycle with exogenous environmental cyclic events.

Acknowledgements. We thank $\mathrm{J}$. Hacunda for his assistance in field and laboratory, and Prof. E. Bünning and Prof. A. Seilacher for helpful discussions. This study received support from the Sonderforschungsbereich 53 'Palökologie' (D 30) of the 'Deutsche Forschungsgemeinschaft', from National Science Foundation grants OCE 75-14374, 75-19026 and 76-02202, and from the Vollmer Foundation through the Bermuda Biological Station. This publication is Sonderforschungsbereich 53 Konstruktionsmorphologie No. 111, Bermuda Biological Station Contribution No, 800, and LamontDoherty Geological Observatory Contribution No. 2848.

\section{LITERATURE CITED}

Bé, A. W. H. (1960). Ecology of Recent planktonic foraminifera: Part 2 - Bathymetric and seasonal distributions in the Sargasso Sea off Bermuda. Micropaleontology, 6, 373-392.

Bé, A. W. H. and Anderson, O. R. (1976). Gametogenesis in planktonic foraminifera. Science, N. Y., 192, 890-892.

Bé, A. W. H., Vilks, G. and Lott, L. (1971). Winter distribution of planktonic foraminifera between the Grand Banks and the Caribbean. Micropaleontology, 17, 31-42.
Bé, A. W H., Hemleben, C., Anderson, O. R., Spindler, M. Hacunda, J. and Tuntivate-Choy, S. (1977). Laboratory and field observations of living planktonic foraminifera. Micropaleontology, 23, 155-179.

Berger, W. H. (1969). Ecologic patterns of living planktonic Foraminifera. Deep Sea Res., 16, 1-24

Berger, W. H. (1970). Planktonic Foraminifera: differential production and expatriation off Baja California. Limnol. Oceanogr., 15, 183-204

Berger, W. H. (1971). Sedimentation of planktonic Foraminifera. Mar. Geol., 11, 325-358.

Berger, W. H. and Soutar, A. (1970). Preservation of plankton shells in an anaerobic basin off California. Bull. geol. Soc. Am., 81, 275-282.

DeCoursey, P. J. (Ed.) (1976). Biological Rhythms in the Marine Environment, University of South Carolina Press, Columbia.

Enright, J. T. (1975). Orientation in time: endogenous clocks. In O. Kinne (Ed.), Marine Ecology, Vol. II, Physiological Mechanisms, Part 2. Wiley, London. pp. 917-944.

Kinne, O. (Ed.) (1970). Marine Ecology, Vol. I, Environmental Factors, Part 1, Wiley, London.

Kinne, O. (Ed.) (1971). Marine Ecology, Vol. I, Environmental Factors, Part 2, Wiley, London.

Kinne, O. (Ed.) (1972). Marine Ecology, Vol. I, Environmental Factors, Part 3, Wiley, London.

Saunders, D. S. (1977). An Introduction to Biological Rhythms, Blackie, Glasgow.

Spindler, M., Anderson, O. R., Hemleben, C. and Bé, A. W. H. (1978). Light and electron microscopic observations of gametogenesis in Hastigerina pelagica (Foraminifera). $J$. Protozool., 25, 427-433.

This paper was submitted to the editor; it was accepted for printing on May 28, 1979. 